\title{
Increasing active travel: aims, methods and baseline measures of a quasi-experimental study
}

\author{
Ralph Chapman ${ }^{1 *}$, Philippa Howden-Chapman², Michael Keall², Karen Witten³ ${ }^{3}$ Wokje Abrahamse ${ }^{1}$, \\ Alistair Woodward ${ }^{4}$, Dylan Muggeridge ${ }^{1}$, Jean Beetham ${ }^{1}$ and Mark Grams ${ }^{1}$
}

\begin{abstract}
Background: Policy advisers are seeking robust evidence on the effectiveness of measures, such as promoting walking and cycling, that potentially offer multiple benefits, including enhanced health through physical activity, alongside reductions in energy use, traffic congestion and carbon emissions. This paper outlines the 'ACTIVE' study, designed to test whether the Model Communities Programme in two New Zealand cities is increasing walking and cycling. The intervention consists of the introduction of cycle and walkway infrastructure, along with measures to encourage active travel. This paper focuses on the rationale for our chosen study design and methods.
\end{abstract}

Method: The study design is multi-level and quasi-experimental, with two intervention and two control cities. Baseline measures were taken in 2011 and follow-up measures in 2012 and 2013. Our face-to-face surveys measured walking and cycling, but also awareness, attitudes and habits. We measured explanatory and confounding factors for mode choice, including socio-demographic and well-being variables. Data collected from the same households on either two or three occasions will be analysed using multi-level models that take account of clustering at the household and individual levels. A cost-benefit analysis will also be undertaken, using our estimates of carbon savings from mode shifts. The matching of the intervention and control cities was quite close in terms of socio-demographic variables, including ethnicity, and baseline levels of walking and cycling.

Discussion: This multidisciplinary study provides a strong design for evaluating an intervention to increase walking and cycling in a developed country with relatively low baseline levels of active travel. Its strengths include the use of data from control cities as well as intervention cities, an extended evaluation period with a reasonable response rate from a random community survey and the availability of instrumental variables for sensitivity analyses.

Keywords: Methods, Cycling, Walking, Quasi-experimental, Physical activity, Active travel, Attitudes, New Zealand

\section{Introduction}

Alongside intensifying global problems of climate change and energy insecurity sits the more local but connected issue of insufficient physical activity, the health effects of which are evident in rising global rates of diabetes and many other non-communicable diseases $[1,2]$. Policy advisers are seeking further evidence on the effectiveness of policy measures, such as promoting walking and cycling, that potentially offer multiple benefits, including enhanced health through physical activity, and reductions in energy use, traffic congestion and carbon emissions [3].

\footnotetext{
*Correspondence: ralph.chapman@vuw.ac.nz

${ }^{1} N Z$ Centre for Sustainable Cities, and Victoria University of Wellington, Environmental Studies Programme, SGEES, P.O. Box 600, Wellington, New Zealand

Full list of author information is available at the end of the article
}

Consistent with the dearth of research on the effectiveness of health policy initiatives [4], several systematic reviews have shown that there is little robust evidence concerning effective interventions to increase walking and cycling $[5,6]$. The aim of this paper is to describe the design, implementation, strengths and limitations of a quasi-experimental study of an intervention to increase active travel (walking and cycling).

The New Zealand Model Communities Programme (MCP) was jointly funded from mid-2010 by central and local government and provided an opportunity for a 'natural experiment'. Our study was initially funded by small grants from the two MCP councils and the researchers' universities, and then in 2012 by central government as part of a competitive research grant. The research group was independent of both the New Zealand Transport 
Agency, which channelled the MCP's central government funding, and the two local governments involved in the MCP's funding and implementation. However, using the principles and practices of partnership [7,8], we established strong working relationships with the four local governments involved.

\section{Background}

Insufficient physical activity is responsible for an estimated 3.2 million deaths per year globally [2]. Longterm observational studies have reported that individuals who walk and cycle regularly experience lower rates of cardiovascular disease (CVD), cancer, and other diseases [9-11]. However, interventions to promote cycling have not generally resulted in an increase in overall physical activity, or sustained reductions in body mass [12]. Two recent reviews have shown limited evidence for slowing weight gain amongst adults [13], but promising evidence for reducing diabetes [14]. Amongst children and adolescents, walking or cycling to school has been linked with improved cardiorespiratory fitness [15], muscular fitness (equivocal) [16] and lower weight (weak) [17].

New Zealand has high rates of car ownership and an increasing rate of obesity and diabetes. The New Zealand Census and the Household Travel Survey show a decline to around 2006 in active travel and substantial decreases in cycling and walking for children aged 5-14, and in cycling among teenagers, in the last two decades $[18,19]$. Recent Travel Survey data suggest that cycling is now starting to increase for larger cities ( $>100,000$ residents), but may still be declining for most smaller cities, and that walking may still be declining.

Research indicates that mode shift towards active travel is difficult to achieve without sustained effort $[20,21]$. It is difficult to change long-standing and complex patterns of habitual behaviour in the face of pervasive social, economic and environmental forces such as highway building which maintain the status quo, or support increased car use. In addition, social investment in promoting physical activity, and particularly active travel, is currently limited by a lack of evidence on the nature of the institutional barriers to active travel investment, but it appears that few countries' institutions effectively integrate public health and urban planning considerations in decision making [11]. Whether this is amenable to integrated national action plan development $[22,23]$ remains unclear.

Recent reviews have summarised current knowledge about encouraging walking and cycling [21,24-27]. Ogilvie and colleagues reported that a range of interventions, including publicity campaigns and various engineering measures, have been tested and not been effective in causing a significant shift from car trips to walking and cycling [28]. They later concluded that community-wide promotional activities, in conjunction with improving infrastructure for cycling, may increase cycling by modest amounts, but there is a need for more precise measures of travel activity to assess behaviour change, with a focus on areas without an established cycling culture [12].

A review by Pucher and colleagues concluded that there were clear increases in cycling activity associated with: infrastructure interventions, such as bike-lanes and parking; integration with public transport; education and marketing programmes; bicycle access programmes; and changes in laws related to active transport [21]. They found that targeted interventions have achieved measurable mode shifts in some settings, but concluded that substantial increases in cycling will require a combination of many different interventions including improved physical infrastructure, pro-bicycle educational programmes, supportive land use planning and restrictions on car use. That is, a package may perform better than its constituent parts.

Most of the studies that were included in these systematic reviews were cross-sectional in nature and had significant limitations in their design and measurement. In short, there remain gaps in our understanding of the efficacy and relative importance of interventions to increase walking and cycling. There have been few experimental or quasi-experimental studies [29] and a large US controlled study, with four experimental communities and one control community, detected no significant changes [30]. The iConnect longitudinal study of cycling and walking is being carried out in a number of UK sites, but does not include control sites [31,32]. In New Zealand, some cross-sectional research exists [33] and in Australia a study is being undertaken to evaluate a cycle system extension in Sydney using a control area and 2year follow-up, with outcome variables to include quality of life impacts [34]. To our knowledge there are no completed systematic community trials of interventions to increase walking and cycling, which have included the broad range of outcomes we have included in our study.

\section{Safety concerns and the urban environment}

Choice of travel mode is generally influenced by perceptions of safety $[35,36]$. As cycling increases, injury rates tend to fall, making cycling safer and providing larger net health benefits [37-39]. It is proposed that cyclists become more visible to motorists as the number of cyclists grows and a higher proportion of motorists are likely to be cyclists themselves and therefore more sensitive to the needs and rights of cyclists [21]. This change tends to lead to public and political support for more investment in cycling and pedestrian infrastructure, but in highly car-dominated cities, small increases in cycling may not achieve the "safety in numbers" effect. 
Many aspects of the urban environment influence the attractiveness of walking and cycling: greater numbers of bicycling lanes and pedestrian paths can induce more active travel [21]; and greater street connectivity can improve access and thus induce more active travel [40]. Topography, weather and green spaces influence both active travel and motorised travel [35,41], but whether there is a link between urban open space and active trips is unclear, with results varying by age group and place $[42,43]$. Rates of cycling to work or school fluctuate seasonally, with low rates in winter [44].

\section{The influence of attitudes and habits}

Attitudes consistent with the dominant car culture (e.g. "car drivers pay for the road and should always be given right-of-way") as well as custom and habit, appear to be associated with the level of walking and cycling [21]. Increasing people's awareness of the benefits of active travel may help in increasing it, although attitudes and perceptions differ across population groups. For example, a Melbourne study found women were more concerned about risks associated with sharing road space with motor vehicles, and this suggests that better off-road facilities could support cycling uptake among women, who are currently under-represented as cyclists [45].

Another psychological construct that seems to strongly influence walking and cycling is habits, generally defined as goal-directed and automated behaviour [46]. For instance, somebody may automatically always drive to the local store. This habit will only change, when the situation changes substantially, i.e. a new cycle route encourages the person to try cycling, instead of driving, to the local shop. The MCP programme presents a unique opportunity to examine whether habitual behaviours change as a result of infrastructural changes.

Studies on travel mode choice have typically examined habits in relation to car use [47]. The concept of habit does not seem to have been used in research on walking, and in only one study of cycling. That study found that habit strength was the strongest predictor of cycling to work, even after variables derived from the theory of planned behaviour (attitudes towards cycling, social norms in favour of cycling, and perceived ability to cycle) and socio-demographic variables were controlled for [48].

\section{Social gradients in walking and cycling}

Compared with other forms of activity, walking and cycling seem less likely to show a social, cultural or economic gradient, although this varies by place and time. Analysis of national New Zealand Travel Survey data from 2003-2007 does not show a socio-economic gradient in bicycle travel and there is no gradient in walking apart from higher levels of walking amongst people with annual income less than $\$ 10,000$ [49,50]. It is desirable that this equality is maintained with new interventions at a city level. One study addressing socio-economic grade in the uptake of cycling, the study of the Six Cycling Demonstration Towns in the UK, found that there was an increase in propensity to cycle associated with the intervention across all socio-economic grades [51]. Both the Marmot Review in the UK [52] and the WHO Commission on the Social Determinants of Health have noted the importance of increasing the proportion of people from low-income communities walking and cycling [53].

\section{The Model Communities Programme (MCP)}

In early 2010 the New Zealand Transport Agency sought tenders from local councils to establish the MCP, with the aim of encouraging the uptake of walking and cycling through structural changes and educational efforts. The MCP aimed to deliver safe, urban environments that would encourage 'novice users' to walk or cycle to school or to work in fully integrated walking and cycling transport networks [54]. Two North Island local governments, New Plymouth District Council and Hastings District Council were selected based on the central government's criteria, and were funded $\$ 4.9$ million and $\$ 4.3 \mathrm{~m}$. respectively from July 2010 to July 2012. New Plymouth and Hastings are small cities of approximately the same population and latitude (Figure 1); both are largely suburban cities, with very few townhouses or apartment buildings. New Plymouth has a lower proportion of its population who are Māori (the indigenous population) (15\%) compared to Hastings (24\%), but median incomes are similar, as are median ages (Table 1).

The cities developed their programmes in line with local aims and were branded Let's Go in New Plymouth and $i$ Way in Hastings, but the strong similarities mean that they can usefully be evaluated side by side. Programme similarities include:

- Infrastructure upgrading and new investment, e.g. footpath renewal, new tracks, new cycle paths, lighting, bike stands, shared space or pathway projects, etc.

- Publicity and awareness campaigns for attitudes towards walking and cycling

- Safety for both communities involves a combination of education and infrastructure investment, e.g. safety education in schools, targeting young people

- A connectivity and spatial emphasis for key areas such as CBD, schools and residential areas

- Travel plan support through mapping and internet-based schemes

- Integration, in the sense of involvement of other government agencies, community groups and schools to help achieve objectives. 


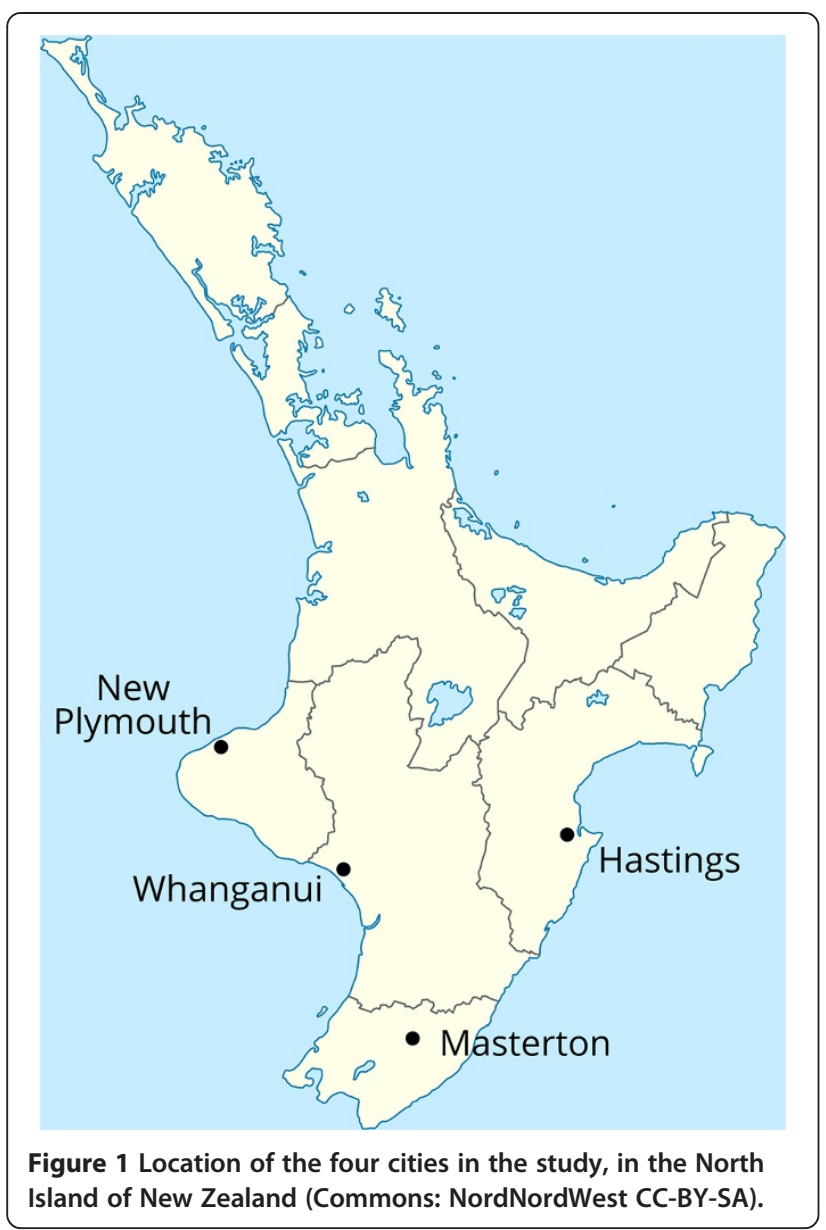

The differences between the programmes are relatively minor: New Plymouth includes visitors as a target group; Hastings focuses more on arterial routes (separated shared pathways that link Hastings to surrounding communities); and some sub-programmes are distinct, such as New Plymouth's 'dream street' concept, an initiative to encourage local communities to re-design their street.

\section{Methods/Design}

\section{The ACTIVE study design}

The 'Activating Communities to Improve Vitality \& Equality' (ACTIVE) study was designed to robustly evaluate the MCP by assessing whether, as a result of the interventions, there is a change in the amount of walking and cycling to work and study (primary outcome), total walking and cycling physical activity, walking and cycling habits, attitudes and awareness. While the intervention cities have undertaken a range of before-and-after traffic and travel counts and surveys, as a way of evaluating their programmes [55], firm causal inferences cannot be drawn from these data in the absence of control data.

As suitably matched control cities, we selected two North Island cities, Whanganui and Masterton (Figure 1), which have similar demographic populations, economic profiles and climates to the intervention cities. The control cities are both interested in promoting active travel, but have not received central government money for this purpose. A study design of this kind sheds light on whether changes observed over time in the intervention cities are likely to be due to the intervention programmes and are not part of a wider trend. This form of quasi-experimental study, while not a randomised control trial, controls for internal validity more than other evaluation methods (such as simple before-and-after studies) and enables some causal inferences to be drawn $[56,57]$.

We first established a logic model to ensure that we had correctly identified the mediating and outcome variables [58] (Figure 2). Evaluations of behaviour change programmes are strengthened when not only the outcomes, but also possible mediating factors that lead to the behaviour change, are measured and correlate with the main outcome measure.

The primary aim of our study is to assess whether the MCP interventions result in an increase in walking and cycling to work or study, and an increase in physical

Table 1 Socio-demographic and climatic data for the four cities (territorial authorities)

\begin{tabular}{|c|c|c|c|c|c|}
\hline & \multicolumn{2}{|c|}{ Intervention cities } & \multicolumn{2}{|c|}{ Control cities } & \multirow[b]{2}{*}{$\mathrm{NZ}$} \\
\hline & New Plymouth & Hastings & Whanganui & Masterton & \\
\hline Estimated resident pop. & 71,100 & 73,200 & 43,800 & 23,200 & $4,184,600$ \\
\hline Pop. in 10-19 age-group (\%) & 15.0 & 16.2 & 15.6 & 15.6 & 14.9 \\
\hline Median age & 38.7 & 36.6 & 39.7 & 40.4 & 35.9 \\
\hline Māori pop. & 10,300 & 17,800 & 9,800 & 4,000 & 624,300 \\
\hline Māori \% of pop. & 14.5 & 24.3 & 22.4 & 17.2 & 14.9 \\
\hline Median income, people 15 \& over & 22,800 & 22,600 & 19,800 & 21,700 & 24,400 \\
\hline Mean air temp. August/Feb, ${ }^{\circ} \mathrm{C}$ & $10.3 / 18.0$ & $10.3 / 19.4^{*}$ & $10.2 / 18.5$ & $8.4 / 17.7$ & \\
\hline Mean annual rainfall (mm) & 1386 & $785^{*}$ & 918 & 928 & \\
\hline
\end{tabular}

*The air temp and rainfall given are for Napier, an immediately adjacent city. Sources: Statistics New Zealand, 2006 Census data. 


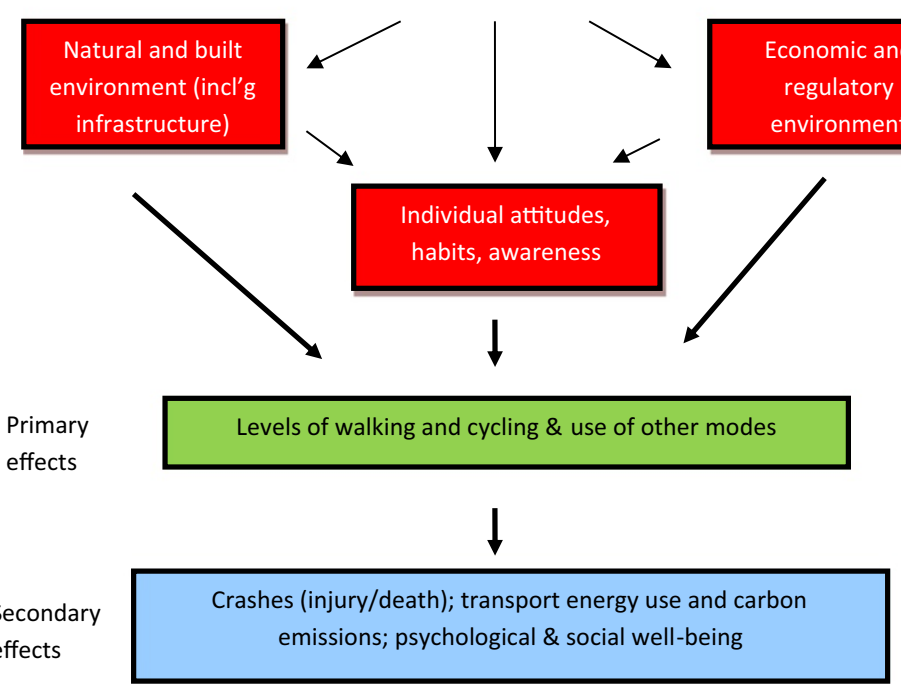

Figure 2 Schematic diagram of the 'ACTIVE' study design.

activity (including recreational walking and cycling). Secondary aims are to:

- assess whether changes in the number and proportion of active travel trips within the intervention communities varies between areas with different levels of socio-economic deprivation, taking into account access distance to MCP infrastructure;

- assess whether there is a mode shift from car use, and any change in public transport use, alongside any increase in active travel;

- assess changes in pedestrian and cyclist injury and death rates associated with the intervention;

- measure any change in mode-related habitual behaviour, awareness of informational and media campaigns, and attitudes towards cycling/walking, among those who did and did not increase their use of walking and cycling during the study period;

- assess the MCP's overall costs and benefits (including estimated health benefits, and energy and carbon savings from mode substitution).

\section{Settings}

While the control cities have substantially smaller populations than the intervention cities, according to the 2006 Census, the socio-demographic characteristics of the populations in the four cities are similar (Table 1). As the four cities are relatively close together geographically, the climatic data are also similar, although annual rainfall in the intervention cities averaged 18\% higher than in the control cities.
The transport characteristics of the four cities at the 2006 Census (prior to the intervention) were also relatively similar (Table 2); for example, the percentage cycling to work ranges from 2.0\% (New Plymouth) to 3.3\% (Whanganui). As they are all provincial cities with ample car parking, the proportion of Census respondents using a bus for the journey to work is very low, at $0.3-0.4 \%$; and access to two or more vehicles per household is common (44\% in Whanganui to 56\% in Hastings).

\section{Sampling frame}

Power calculations were as follows. Assuming a 60\% response rate and then $60 \%$ retention on follow-up, it was estimated that 1,200 households would need to be sampled, with equal numbers in the intervention and control cities. In the control cities, the proportion of noncyclists at baseline who are active cyclists at follow-up could be expected to be about $2 \%$. Based on expert opinion and the Demonstration Towns study in the UK [51], we anticipated that the intervention could increase this proportion in the combined intervention cities to $6 \%$, which could be detected from an attained total sample size of 430 (215 households per group) with $80 \%$ power and Type I error probability associated with the null hypothesis of 0.05 . To allow for a reduced effective sample size due to clustering of respondents at the household level, the sample size was conservatively calculated as though there were only one response per household, even though all household members 10 years of age and over were asked to participate in the Household Survey. 
Table 2 Travel to work, and access to motor vehicles, for the four cities

\begin{tabular}{lccccccc}
\hline & New Plymouth & Hastings & $\begin{array}{c}\text { Intervention cities } \\
\text { (weighted average) }\end{array}$ & Whanganui & Masterton & $\begin{array}{c}\text { Control cities } \\
\text { (weighted average) }\end{array}$ & $\begin{array}{c}\text { New Zealand } \\
\text { Walked or jogged (\%) }\end{array}$ \\
Cycled (\%) & 5.3 & 4.0 & 4.6 & 5.3 & 5.2 & 5.3 & 5.3 \\
Public bus (\%) & 2.0 & 2.7 & 2.4 & 3.3 & 2.8 & 3.1 & 0.3 \\
Households with access to & 0.4 & 0.3 & 0.3 & 0.3 & 0.3 & 4.9 & 3.0 \\
2 or more motor vehicles (\%) & 51.8 & 55.7 & 53.8 & 44.0 & 49.2 & & 45.8 \\
\hline
\end{tabular}

Sources: Statistics New Zealand. 2006 Census data.

The random sample drawn was based on lists of addresses of ratepayers supplied to us by the four district councils (territorial authorities), limiting the selection to the urbanised parts of the four districts. We focused on these areas since the intervention infrastructure investment is focused in the urban parts of the districts. The Census data for the four districts relate to a greater rural area than the urban areas from which we drew our sample, so we would expect some differences between Census averages and our sample baseline variable averages. Intervention households were randomly selected from strata defined by areas close to, and distant from, MCP infrastructure, and by low and high socio-economic deprivation mesh-blocks.

The response rate for the baseline Household Survey carried out over winter 2011 was 38.0\% (the number of households with completed questionnaires divided by the number of eligible households, after sample loss due to houses not being occupied, or found to be commercial premises, etc.). Sample numbers and response rates are shown in Figure 3, and described further below, but in short, 521 participants in 400 households were surveyed in 2011. In 2012, combined with a supplementary sample of 127 households, there was a $48.9 \%$ response rate, giving 322 households (458 people). In 2013, there was a response rate of $55.3 \%$ of households, giving a final year sample of 230 households (283 respondents).

\section{Data collection method}

Sample households were initially sent an introductory letter and information sheet which asked them to participate in a study which involved them being interviewed about their walking, cycling and transport habits and views, and general well-being. Children aged 10 years and over were given a specially tailored and simplified information sheet. We sought consent, including from children in the presence of their parents, and in all cases, agreement to complete the face-to-face interview was taken as consent. All participants were interviewed at home and children were interviewed in the presence of their parents. Parents were able to refuse if they did not want their children to participate. Ethical approval for the study method was granted by the University of Otago Human Ethics Committee (Category A -involving children-11/107).
Baseline survey data were collected first in each city in mid-2011. Interviews were carried out by teams of trained students from the local polytechnics and experienced interviewers. Follow-up interviews were undertaken in the next two years, 2012 and 2013, at the same time of year. In the 2013 survey we employed all professional interviewers.

To offset sample loss after the baseline year, some additional households were added to the randomly drawn sample in 2012 and followed up in 2013, adding sample for the longitudinal comparisons (2011-2013, 2011-2012, 2012-2013). Additional approval was obtained from the Ethics Committee to go into a draw for a NZ \$300 grocery voucher. As specified a priori in our study design, the data from the two intervention cities will be combined in the analysis to gain sufficient statistical power. Changes in travel behaviour in these cites over the same interval will be compared with the combined data from the control cities.

The distribution of the respondents in the four cities in the ACTIVE baseline survey sample (Table 3) can be compared to the distribution in the 2006 Census (Tables 1 and 2). There is some sampling bias toward female respondents and older respondents, compared with the Census. This may be due to women being more available to respond to surveys, and younger people (below 20 years) being significantly less often at home when interviewers called, although up to three call-backs were made by interviewers. However, low income groups were proportionally represented; for example, 39\% in the intervention and 43\% in the control cities respectively had personal incomes below $\$ 20,000$, while at the Census, $50 \%$ had incomes below $\$ 22,000$ (weighted median in Table 1 is $\$ 22,000$ ). No important divergence from the Census was found for ethnicity (a sample average of $18.7 \%$ were Māori, while an average of $19.8 \%$ were Māori at the Census).

Transport behaviours at the 2011 baseline are also reported in brief (trip to work only, for comparability with the 2006 Census) in Table 3. The sample's proportion walking or running to work was 8 and 11\% (intervention and control cities), compared with $5 \%$ for both pairs of cities at the Census, which may reflect the greater rural area in the Census. Similarly, the proportion of trips to work by bicycle was $4 \%$ and $5 \%$ (against $2 \%$ and $3 \%$ at the Census) and by bus was $1 \%$ and $0 \%$ ( $0 \%$ and $0 \%$ at the Census). 


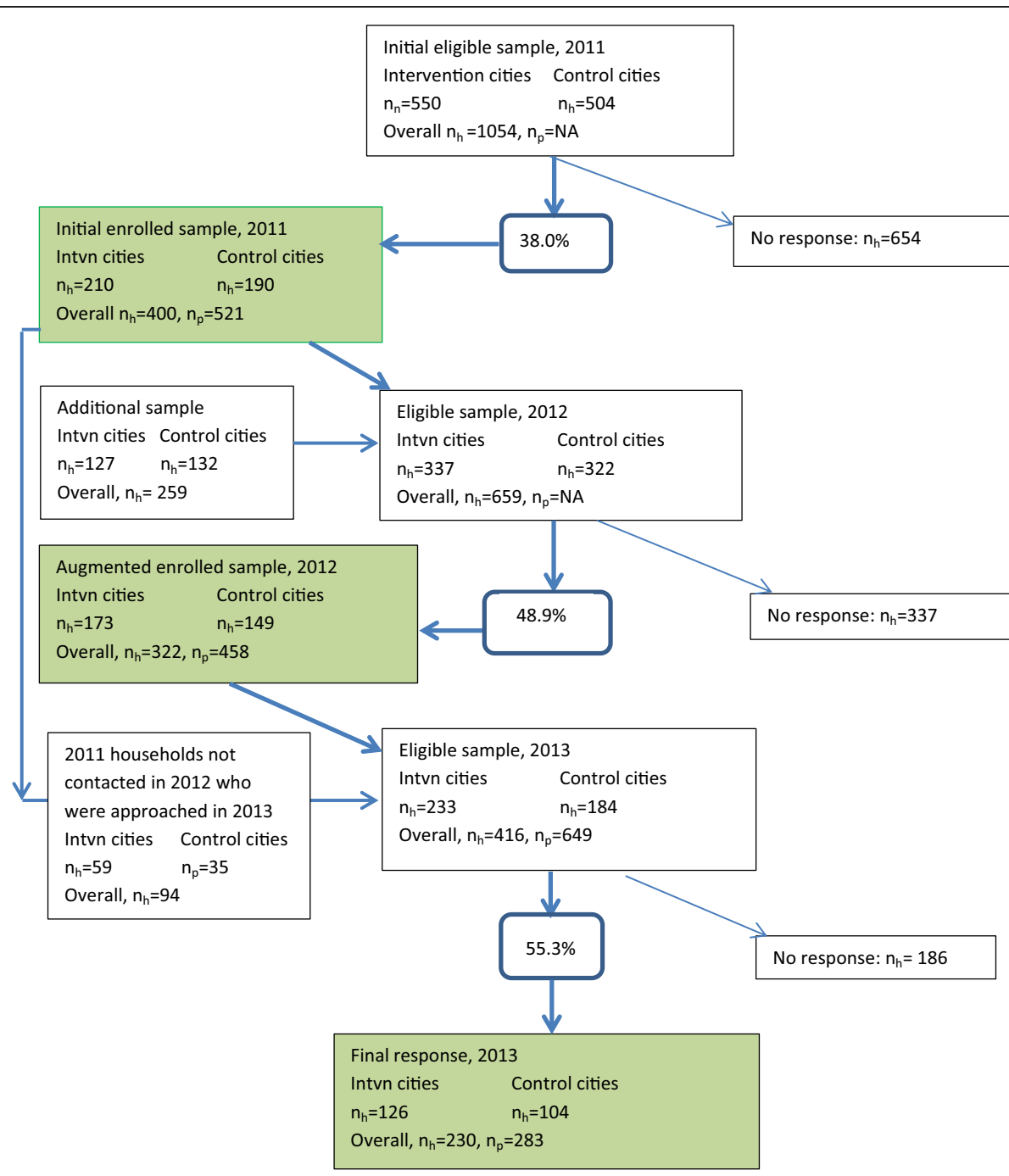

Key:

$n_{h}=$ Number of households; $n_{p}=$ Number of participants;

NA=Number not available as the number of eligible household members could not be determined ex ante

Figure 3 ACTIVE study sample flow diagram.

To assess whether mode choices were influenced by lack of access to modes such as bicycles, we investigated access to bikes and cars, and presence of a physical disability among respondents. The 2011 baseline data showed that $56 \%$ and $50 \%$ (intervention and control cities) reported having access to a functioning bike, while $92 \%$ and $84 \%$ had access to a car. Overall some $14 \%$ reported a physical condition that prevented respondents walking or cycling in the last 7 days. Questions to describe baseline walking and cycling activity were based on IPAQ conventions [59]; these showed that at the baseline, such activity had a higher prevalence in the intervention than in the control cities (18\% more walking in the intervention cities; $26 \%$ more cycling).
Supplementary data included: an intercept survey of cyclists in Hastings and New Plymouth, and qualitative data from focus groups and interviews in Hastings. The purpose of the intercept survey was, following Ogilvie [28], to enable a more nuanced evaluation of whether any increased active travel arises from new people participating, or people who were already walking/cycling at the beginning of the MCP increasing their activity. A clearer picture of this is potentially significant for assessing the value of the benefits of the MCP. A qualitative study in Hastings explored the factors influencing people's active travel, especially the factors influencing their walking and cycling behaviour patterns, and their awareness of $i$ Way at an early stage in the programme. 
Table 3 Baseline information for the intervention and control cities

\begin{tabular}{|c|c|c|c|c|c|c|}
\hline & New Plymouth & Hastings & Intervention cities total & Whanganui & Masterton & $\begin{array}{l}\text { Control } \\
\text { cities total }\end{array}$ \\
\hline \multicolumn{7}{|c|}{ Individual socio-demographic factors at baseline (2011 sample +2012 additions) } \\
\hline $\begin{array}{l}\text { No. of persons responding } \\
\text { (2011 plus new in 2012) }\end{array}$ & 209 & 195 & 404 & 222 & 137 & 359 \\
\hline Age $(\%<20)$ & $11 \%(22 / 202)$ & $19 \%(36 / 190)$ & $15 \%(58 / 392)$ & $16 \%(31 / 200)$ & $11 \%(14 / 125)$ & $14 \%(45 / 325)$ \\
\hline$(\%$ 60+) & $33 \% 66 / 202)$ & $22 \%(42 / 190)$ & $28 \%(108 / 392)$ & $33 \%(66 / 200)$ & $33 \%(41 / 125)$ & $33 \%(107 / 325)$ \\
\hline Sex (\% female) & $60 \%(125 / 208)$ & $63 \%(122 / 195)$ & $61 \%(247 / 403)$ & $61 \%(136 / 222)$ & $64 \%(86 / 135)$ & $62 \%(222 / 357)$ \\
\hline Ethnicity (\% Maori) & $15 \%(24 / 165)$ & $21 \%(39 / 182)$ & $18 \%(63 / 347)$ & $20 \%(33 / 168)$ & $19 \%(20 / 104)$ & $19 \%(53 / 272)$ \\
\hline (\% European) & $75 \%(123 / 165)$ & $69 \%(126 / 182)$ & $72 \%(249 / 347)$ & $76 \%(127 / 168)$ & $79 \%(82 / 104)$ & $77 \%(209 / 272)$ \\
\hline Personal income (\% up to $\$ 10,000 / y$ ) & $18 \%(33 / 186)$ & $18 \%(29 / 158)$ & $18 \%(62 / 344)$ & $16 \%(31 / 191)$ & 19\%(20/103) & $17 \%(51 / 294)$ \\
\hline$(\% \$ 10,001-\$ 20,000 / y)$ & $22 \%(40 / 186)$ & $21 \%(33 / 158)$ & $21 \%(73 / 344)$ & $27 \%(51 / 191)$ & $24 \%(25 / 103)$ & $26 \%(76 / 294)$ \\
\hline$(\%>\$ 40,000 / y)$ & $32 \%(60 / 186)$ & $35 \%(55 / 158)$ & $33 \%(115 / 344)$ & $28 \%(54 / 191)$ & $30 \%(31 / 103)$ & $29 \%(85 / 294)$ \\
\hline \multicolumn{7}{|c|}{ Transport behaviours at baseline (2011 sample only) } \\
\hline $\begin{array}{l}\% \text { trips to work (last } 7 \text { days) - } \\
\text { walked or ran }\end{array}$ & $11 \%(35 / 310))$ & $4 \%(11 / 274))$ & $8 \%(46 / 584)$ & $10 \%(32 / 316)$ & $13 \%(29 / 232))$ & $11 \%(61 / 548)$ \\
\hline - cycled & $0 \%(0 / 310)$ & $8 \%(21 / 274)$ & $4 \%(21 / 584)$ & $4 \%(12 / 316)$ & $8 \%(18 / 232)$ & $5 \%(30 / 548)$ \\
\hline - bus & $0 \%(0 / 310)$ & $2 \%(5 / 274)$ & $1 \%(5 / 584)$ & $0 \%(0 / 316)$ & $0 \%(0 / 232)$ & $0 \%(0 / 548)$ \\
\hline - car or other & $90 \%(278 / 310)$ & $86 \%(237 / 274)$ & $88 \%(515 / 584)$ & $86 \%(271 / 316)$ & $80 \%(185 / 232)$ & $83 \%(456 / 548)$ \\
\hline $\begin{array}{l}\text { Access to modes\% access } \\
\text { to a bicycle }\end{array}$ & $53 \%(69 / 131)$ & $59 \%(76 / 128)$ & $56 \%(145 / 259)$ & $43 \%(65 / 152)$ & $60 \%(62 / 104)$ & $50 \%(127 / 256)$ \\
\hline$\%$ access to a car & $91 \%(119 / 131)$ & $94 \%(120 / 128)$ & $92 \%(239 / 259)$ & $79 \%(120 / 152)$ & $92 \%(96 / 104)$ & $84 \%(216 / 256)$ \\
\hline$\%$ with physical disability & $15 \%(19 / 131)$ & $14 \%(18 / 128)$ & $14 \%(37 / 259)$ & $16 \%(24 / 152)$ & $11 \%(11 / 104)$ & $14 \%(35 / 256)$ \\
\hline \multicolumn{7}{|c|}{ Physical activity behaviours at baseline (2011 sample only) } \\
\hline $\begin{array}{l}\text { Hrs walking (mod + vigorous) } \\
\text { last } 7 \text { days }\end{array}$ & 3.6 & 4.4 & 4.0 & 3.2 & 3.5 & 3.4 \\
\hline $\begin{array}{l}\text { Hrs cycling (reg + vigorous) } \\
\text { last } 7 \text { days }\end{array}$ & 0.25 & 0.80 & 0.53 & 0.20 & 0.64 & 0.42 \\
\hline
\end{tabular}

\section{Outcome measures}

Although the main outcome measure was derived from survey data on longitudinal changes in individual travel and mode choice, secondary data sources were also available. The key outcome variables were numbers and distances walking or cycling to work or study, and time spent in walking and cycling physical activity. Multilevel data were collected at city (district council), household and individual level (Table 4). As we were able to code the geographical position of each respondent's house, we were not only able to quantify the distance of each individual to their nearest upgraded cycle-way/ walkway, but also to their reported workplace/school.

The individual household survey data were supplemented by a before-and-after 'hands-up' school survey of mode use. With assistance from the councils involved, we accessed road survey data of vehicle, cyclist and pedestrian counts conducted before, during and after the intervention.

\section{Data analysis and methodological issues}

The main level of analysis will be at the level of the city (intervention vs control), mediated by individual exposure to the infrastructure component of the MCP interventions. This exposure is partially determined by geographic factors such as where individuals live, work, study; and how and where they travel, as well as their exposure to traffic. This, in turn, reflects individual demographic and lifestyle factors such as age, sex, social class, income, job, and mode of travel, influencing the way people lead their daily lives.

The follow-up measures will enable calculation of any changes in active travel behaviour attributable to the intervention, as well as any increase in relative inequalities in active travel behaviour. We will fit multi-level regression models on the available survey data on travel behaviour, which include national data being collected at the same time as the survey described here. The models will estimate individual change in mode choice using the data at 
Table 4 Outcome and other variables and their levels

\begin{tabular}{|c|c|c|c|}
\hline Level & Source & Variable & Measures \\
\hline \multicolumn{4}{|c|}{ Outcome measures } \\
\hline \multirow[t]{3}{*}{ City } & Ministry of Health & Road crash injuries & Hospitalisations (no.) \\
\hline & & & Deaths (no.) \\
\hline & Selected schools & Mode of travel to school & Hands up in school' surveys: Frequency by mode (no.) \\
\hline \multirow[t]{12}{*}{ Individual } & Face-to-face survey & Distance and time by journey purpose & $\begin{array}{l}\text { Work/study/shopping/leisure/accompanying } \\
\text { family or friends (km, minutes) }\end{array}$ \\
\hline & & Distance and time by mode & Walk-run/cycle/bus/car/other (km, minutes) \\
\hline & & Physical activity (walking) & Days moderate/vigorous walking in last 7 (no.) \\
\hline & & & Time taken, moderate/vigorous walking (hrs) \\
\hline & & Physical activity (cycling) & Days regular/vigorous cycling in last 7 (no.) \\
\hline & & & Time taken, regular/vigorous cycling (hrs) \\
\hline & & & Frequency of cycling, last 4 weeks/12 months (no.) \\
\hline & & Public transport use & Frequency, last 4 wks/12 months (no./yes or no) \\
\hline & & Attitudes affecting mode choice & Rating \\
\hline & & Habits, perceptions of modes & Mode choice for regular activities, ratings \\
\hline & & Awareness of MCP & Yes/no; Source of awareness; participation \\
\hline & & Well-being in recent weeks & SF36 short form ratings \\
\hline \multicolumn{4}{|c|}{ Independent variables and potential confounders } \\
\hline \multirow[t]{4}{*}{ City } & NZ Census 2006, 2013 & Population growth & People (no.) \\
\hline & & Average personal income & Personal income before tax (\$) \\
\hline & District council & Traffic levels & On-road traffic counts (cyclists, pedestrians, cars) (no.) \\
\hline & NZ Census 2006 & Small-area socio-economic deprivation & NZDep index \\
\hline \multirow[t]{5}{*}{ Household } & Face-to-face survey & Modal access & Access to a functioning bicycle (yes/no) \\
\hline & & & Access to a car (yes/no) \\
\hline & Google Maps & Distance to infrastructure & Home-infrastructure distance (km) \\
\hline & www.walkscore.com & Accessibility to local destinations & Walkability score (index) \\
\hline & www.walkscore.com & Accessibility to CBD & Transit score (index) \\
\hline \multirow[t]{8}{*}{ Individual } & Face-to-face survey & Distance to work & Home-work distance (km) \\
\hline & & Distance to study & Home-study distance (km) \\
\hline & & Age & Years \\
\hline & & Ethnicity & Group \\
\hline & & Sex & $M / F$ \\
\hline & & Personal income & Personal income before tax ( $\$$ band $)$ \\
\hline & & Employment status & $\begin{array}{l}\text { Category (Student/Worker/Seeking work/Looking } \\
\text { after home or family/Retired/Other beneficiary) }\end{array}$ \\
\hline & & Physical condition & Disabling physical condition in last 7 days (yes/no) \\
\hline
\end{tabular}

the household level, extrapolated to the intervention and control cities. As the construction of the infrastructure continued over the period spanned by the survey, a factor in the model will measure whether any changes in the intervention cities relative to the control cities continued incrementally with time.

Secondary analyses will be carried out on outcomes including attitudes to travel, counts of cyclists and pedestrians, and road crashes (injury/death).

\section{Discussion}

Our quasi-experimental ACTIVE study is attempting to increase the robustness of evaluation of walking and cycling programmes, by using a stratified random sample of participants in matched intervention and control cities, most of whom have been followed up for two years. The sample appears reasonably aligned with the 2006 Census: although low-income and younger people are under-represented. 
Our baseline measures show that, as expected, driving was the dominant mode; indeed driving (or being driven) was the preferred option for all types of trips, except going to the local park. This preference for car travel does not seem to be predominantly influenced by access to bikes as, though almost everybody had access to a car, over half the sample had access to a bike. A minority of people (14\%) reported a physical condition that prevented them from walking or cycling in the last seven days.

There are a number of strengths to this quasiexperimental study. The study has sufficient power to potentially detect a significant change in cycling and walking behaviour overall, and enable cautious causal inferences to be drawn about the efficacy of the programme. We collected the survey data at approximately the same time each year, during winter/early spring. As these seasons are not ideal for cycling and walking, this may exert a downward effect on active travel levels.

The random sample was classified to let us take account of potential confounders such as socio-economic status. Instrumental variables (the distance of a respondent's dwelling from the major aspect of the intervention, the new structural cycleways and walkways) were measured to enable their potential use in sensitivity analyses.

New Zealand cities' cycling and walking cultures have weakened over the last few decades, although as noted above, in some larger cities there has recently been an increase in cycling. The focus of this study on four smaller cities, all with relatively low levels of walking and cycling, allows us to illuminate the potential for change starting from a low base and facilitates the generalisation of our results to a range of societies dominated by car travel.

Nonetheless, there are a number of important methodological issue in the study, the first being our choice of control cities. As Ogilvie et al. [5], p.122 noted, 'It may... be unrealistic to aspire to anything more than "broadly comparable" control areas' in such studies. While our intervention city samples differ in certain respects from the control city samples, they match them closely in other significant respects, including sociodemographically and ethnically. There were some differences in travel behaviour, with slightly more people walking to work in the intervention cities than in the control cities. On the whole, however, the matching provides confidence that when we later compare the results from the control and intervention cities, the differences are not due to major inter-city differences. A further strength of our study is that we can use other survey data collected by the New Zealand Travel Survey over the study period to supplement the control data collected.

A difficult issue in relation to transport evaluation studies is when to begin collecting baseline data. [5].
Although MCP infrastructural works in principle started from mid-2010, in practice they took time to get underway, so that little had changed on the ground by the time baseline data were collected in mid-2011. However, some promotional activities had taken place, and this may have contributed to some 'baseline awareness' of the two MCP programmes by mid-2011, and possibly a diminishing of the extent of measured changes in behaviours. However, in each year of our study, we measured the participants' awareness of the programmes; for example in mid-2011, only a minority of respondents were aware of the $i$ Way programme.

Other authors of studies in the transport, health and environment area have noted difficulties with low recruitment or response rates (e.g. Saelens et al., [24], p.1557, referring to $15-20 \%$ rates); this, and on-line recruitment of samples, may limit generalizability of findings. However, response rates were relatively high in our study compared to existing studies and we collected longitudinal data, which will be more robust to non-response bias than cross-sectional data.

Our research relationship with local authorities was important. Most district council officers were very helpful, but in a control city, council cycling survey data were not provided, despite reminders. Consequently, a consistent set of cycling data from on-road surveys from all areas studied is not available. Our relationship to the councils also related to the practical, funding issues inherent in evaluating a natural experiment. We were not aware of the MCP until the money had been allocated, which meant that our study was initially very constrained for funds. There were two major consequences on the selection of outcome measures and the choice of interviewers. We focused on proxy health outcomes, such as levels of physical activity, rather than independent health indicators, such as BMI or cardiovascular functioning, largely because of the financial resources available. Similarly, although our use of local polytechnic students, who largely matched the socio-demographics of the cities they lived in, may have strengthened research capacity in these areas and enabled us to begin in a timely fashion, it may have reduced our overall response rate; this was boosted in the final year when we were able to employ professional interviewers. This change in interviewers' experience over the three rounds of the study may also have introduced some instrumentation bias. However, such bias will be the same for both treatment and control cities, so it should not affect the comparisons in travel behaviour that we will estimate.

\section{Conclusion}

Data collection in the ACTIVE study has been successfully concluded. Multivariate analyses will include an assessment of the role of socio-demographic variables in 
explaining changes in levels of active travel to work or study, and physical activity. The data collected will allow comparisons over time and between intervention and control cities, to establish the extent to which the MCP is having an impact on active travel behaviour, and walking and cycling physical activity. We will also be able to establish whether the programme has been successful in significantly affecting crash outcomes, changing travel habits and attitudes, improving reported well-being, and raising public awareness of walking and cycling support.

\section{Competing interests}

The authors declare that they have no competing interests.

\section{Authors' contributions}

RC, PHC and MK conceived the study; RC, PHC, KW, MK, WA and AW participated in its design; RC, PHC, MK, WA, DM, JB and MG implemented it; $\mathrm{RC}, \mathrm{PHC}, \mathrm{KW}, \mathrm{MK}$ and AW drafted the manuscript; all authors read and approved the final manuscript.

\section{Acknowledgments}

The authors wish to thank the many people who generously gave us their time to assist our study. Support from staff and student interviewers at the Eastern Institute of Technology and at Better Homes is gratefully acknowledged. Financial and practical support from Hastings and New Plymouth District Councils, and the practical support of Wanganui and Masterton District Councils and NZTA, are acknowledged with thanks. Financial support from the universities of Otago and Auckland, the Tertiary Education Commission establishment grant for the 'New Zealand Centre for Sustainable Cities' and New Zealand Ministry of Business, Innovation and Employment 'Resilient Urban Futures' grant which includes the ACTIVE study, are also acknowledged. We appreciate the project management contribution of Jan Logie and the comments of Drs Caroline Shaw and Nevil Pierse.

\section{Author details}

${ }^{1} \mathrm{NZ}$ Centre for Sustainable Cities, and Victoria University of Wellington, Environmental Studies Programme, SGEES, P.O. Box 600, Wellington, New Zealand. ${ }^{2}$ Department of Public Health, NZ Centre for Sustainable Cities, University of Otago Wellington, P.O. Box 7343, Wellington South, New Zealand. ${ }^{3} \mathrm{NZ}$ Centre for Sustainable Cities, and Massey University Whariki, Wellesley St, P.O. Box 6137, Auckland, New Zealand. ${ }^{4}$ NZ Centre for Sustainable Cities, and School of Population Health, University of Auckland, 261 Morrin Rd, St Johns, Auckland 1072, New Zealand.

Received: 1 June 2014 Accepted: 29 August 2014

Published: 8 September 2014

\section{References}

1. International Diabetes Federation: Diabetes and Climate Change Report. Brussels: International Diabetes Federation; 2012.

2. WHO: Health in the Green Economy: Health co-benefits of climate change mitigation -Transport sector. In Geneva: World Health Organization; 2011.

3. IPCC, et al: Summary for Policymakers In Climate Change 2014, Mitigation of Climate Change Contribution of Working Group III to the Fifth Assessment Report of the Intergovernmental Panel on Climate Change. Edited by Edenhofer O, Pichs-Madruga R, Sokona Y, Farahani E, Kadner S, Seyboth K, Adler A, Baum I, Brunner S, Eickemeier B, et al. Cambridge, UK, and New York, NY: Cambridge University Press; 2014.

4. Wanless D: Securing good health for the whole population. In London: HM Treasury and Department of Health, HMSO; 2004.

5. Ogilvie D, Mitchell R, Mutrie N, Petticrew M, Platt SD: Evaluating health effects of transport interventions: methodologic case study. Am J Prev Med 2006, 31:118-126.

6. Shaw C, Hales S, Howden-Chapman P, Edwards R: Health co-benefits of climate change mitigation policies in the transport sector. Nature Clim Change 2014, 4(6):427-433.
7. Methods for Community-Based Participatory Research for Health (Second ed.). In Edited by Israel B, Eng E, Schulz AJ, Parker EA. San Francisco: John Wiley \& Sons; 2013.

8. Howden-Chapman P, Crane J, Matheson A, Viggers H, Cunningham M, Blakely T, O'Dea D, Cunningham C, Woodward A, Saville-Smith K, Baker M, Waipara N: Retrofitting houses with insulation to reduce health inequalities: aims and methods of a clustered, randomised community-based trial. Soc Sci Med 2005, 61(12):2600-2610.

9. Hamer M, Chida Y: Active commuting and cardiovascular risk: a meta-analytic review. Prev Med 2008, 46(1):9-13.

10. Giles-Corti B, Foster S, Shilton T, Falconer R: The co-benefits for health of investing in active transportation. New South Wales Public Health Bulletin 2010, 21(6):122-127.

11. Raccioppi F, Dora C, Rutter H: Urban Settings and Opportunities for Healthy Lifestyles: Rediscovering Walking and Cycling and Understanding Their Health Benefits. Built Environ 2005, 31(4):302-314.

12. Yang L, Sahlqvist S, McMinn A, Griffin SJ, Ogilvie D: Interventions to promote cycling: systematic review. British Med J 2010, 341: doi:10.1136/bmj.c5293.

13. Wanner M, Götschi T, Martin-Diener E, Kahlmeier S, Martin BW: Active transport, physical activity, and body weight in adults: a systematic review. Am J Prev Med 2012, 42(5):493-502.

14. Østergaard L, Børrestad LA, Tarp J, Andersen LB: Bicycling to school improves the cardiometabolic risk factor profile: a randomised controlled trial. BMJ Open 2012, 2(6): doi:10.1136/bmjopen-2012-001307.

15. Larouche R, Saunders TJ, Faulkner GEJ, Colley R, Tremblay M: Associations Between Active School Transport and Physical Activity, Body Composition, and Cardiovascular Fitness: A Systematic Review of 68 Studies. J Phys Act Health 2014, 11(1):206-227.

16. Lubans DR, Boreham CA, Kelly P, Foster CE: The relationship between active travel to school and health-related fitness in children and adolescents: a systematic review. Int J Behav Nutr Phys Act 2011, 8(5): doi:10.1186/1479-5868-8-5.

17. Schoeppe S, Duncan MJ, Badland H, Oliver M, Curtis C: Associations of children's independent mobility and active travel with physical activity, sedentary behaviour and weight status: A systematic review. J Sci Med Sport 2013, 16(4):312-319.

18. Tin Tin S, Woodward A, Thornley S, Ameratunga S: Cycling and walking to work in New Zealand, 1991-2006: regional and individual differences, and pointers to effective interventions. Int J Behav Nutr Phys Act 2009, 6(64): doi:10.1186/1479-5868-1186-1164.

19. Keall M, Chapman R, Howden-Chapman P: Changes in frequency of walking and cycling trips in New Zealand: Potential influences of urban form. In Sizing Up The City: Urban form and transport in New Zealand. Edited by Howden-Chapman P, Stuart K, Chapman R. Wellington: Steele Roberts Ltd; 2010:52-57.

20. Steg L, Vlek C: Encouraging pro-environmental behaviour: An integrative review and research agenda. J Environ Psychol 2009, 29:309-317.

21. Pucher J, Dill J, Handy S: Infrastructure, programs, and policies to increase bicycling: an international review. Prev Med 2010, 50:S106-S125.

22. Schweizer C, Racioppi F, Nemer L: Developing national action plans on transport, health and environment: A step-by-step manual for policy-makers and planners. In Transport Health and Environment Pan European Programme. Copenhagen: World Health Organization Regional Office for Europe; 2014.

23. UNECE: Amsterdam Declaration: making THE link: transport choices for our health, environment and prosperity. In Geneva: United Nations Economic Commission for Europe; 2009.

24. Saelens BE, Sallis JF, Black JB: Neighbourhood-based differences in physical activity: an environment scale evaluation. Am J Public Health 2003, 93(9):1552-1558.

25. Pucher J, Dijkstra L: Promoting Safe Walking and Cycling to Improve Public Health: Lessons from The Netherlands and Germany. Am J Public Health 2003, 93:9.

26. Ogilvie D, Foster C, Rothnie H, Cavill N, Hamilton V, Fitzsimons C, Mutrie N: Interventions to promote walking: Systematic review. Br Med J 2007, 334(7605):1204-1207.

27. Powell J, Dalton A, Brand C, Ogilvie D: The Health Economic Case for Infrastructure to Promote ActiveTravel: A Critical Review. Built Environ 2010, 36(4):504-518.

28. Ogilvie D, Egan M, Hamilton V, Petticrew M: Promoting walking and cycling as an alternative to using cars: systematic review. Br Med J 2004, 329(7469):763-767. 
29. Krizek KJ, Handy S, Forsyth A: Explaining changes in walking and bicycling behavior: challenges for transportation research. Environ Planning B 2009, 36:725-740

30. Götschi T, Krizek KJ, McGinnis L, Lucke J, Barbeau J: Nonmotorized Transportation Pilot Program Evaluation Study Phase 2 (CTS 11-13). In Minneapolis, MN: Center for Transportation Studies; 2014.

31. Ogilvie D, Bull F, Powell J, Cooper AR, Brand C, Mutrie N, Preston J, Rutter H: An applied ecological framework for evaluating infrastructure to promote walking and cycling: the iConnect study. Am J Public Health 2011, 101(3):473-481.

32. Goodman A, Sahlqvist S, Ogilvie D: Who uses new walking and cycling infrastructure and how? Longitudinal results from the UK iConnect study. Prev Med 2013, 57(5):518-524.

33. Badland HM, Garrett N, Schofield GM: How does car parking availability and public transport accessibility influence work-related travel behaviors? Sustainability 2010, 2:576-590.

34. Rissel C, Greaves S, Wen LM, Capon A, Crane M, Standen C: Evaluating the transport, health and economic impacts of new urban cycling infrastructure in Sydney, Australia-protocol paper. BMC Public Health 2013, 13(1):963.

35. Heinen $\mathrm{E}$, van Wee B, Maat K: Commuting by Bicycle: An Overview of the Literature. Transp Rev 2010, 30(1):59-96.

36. Van Holle V, Deforche B, Van Cauwenberg J, Goubert L, Maes L, Van de Weghe N, De Bourdeaudhuij I: Relationship between the physical environment and different domains of physical activity in European adults: a systematic review. BMC Public Health 2012, 12(1):807.

37. Elvik R: The non-linearity of risk and the promotion of environmentally sustainable transport. Accident Analysis Prevention 2009, 41:849-855.

38. Jacobsen PL: Safety in numbers: more walkers and bicyclists, safer walking and bicycling. Injury Prevention 2003, 9:205-209.

39. Robinson DL: Safety in numbers in Australia: more walkers and bicyclists, safer walking and bicycling. Health Promotion J Australia 2005, 16(1):47-51.

40. Randall T, Baetz B: Evaluating pedestrian connectivity for suburban sustainability. J Urban Plan Dev 2001, 127:1-15.

41. Boarnet $M$, Crane $R$ : The influence of land use on travel behavior: specification and estimation strategies. Transp Res A 2001, 35:823-845.

42. Hillsdon M, Panter J, Foster C, Jones A: The relationship between access and quality of urban green space with population physical activity. Public Health 2006, 120:1127-1132.

43. Nagel CL, Carlson NE, Bosworth M, Michael YL: The relation between neighborhood built environment and walking activity among older adults. Am J Epidemio/ 2008, 168(4):461-468.

44. Nankervis M: The effects of weather and climate on urban bicycle commuters' decisions to ride; a pilot survey. Road Transport Res 1999, 8:85-97.

45. Garrard J, Rose G, Lo SK: Promoting transportation cycling for women: the role of bicycle infrastructure. Prev Med 2008, 46:55-59.

46. Aarts H, Verplanken B, Van Knippenberg A: Predicting behaviour from actions in the past: Repeated decision making or a matter of habit? J Appl Soc Psychol 1998, 28:1355-1374.

47. Verplanken B, Aarts H, Van Knippenberg A, Moonen A: Habit versus planned behaviour: A field experiment. Br J Soc Psychol 1998, 37:111-128.

48. de Bruijn GJ, Kremers SPJ, Singh A, van den Putte B, van Mechelen W: Adult Active Transportation: Adding Habit Strength to the Theory of Planned Behavior. Am J Prev Med 2009, 36:189-194.

49. Ministry of Transport: Comparing travel modes: Household Travel Survey. v14th edition. Wellington: Ministry of Transport; 2008a.

50. Ministry of Transport: Walking for transport: Ongoing New Zealand Household Travel Survey 2003 - 2007. In Ministry of Transport. Wellington: Ministry of Transport; 2008b.

51. Sloman L, Cavill N, Cope A, Muller L, Kennedy A: Analysis and synthesis of evidence on the effects of investment in six Cycling Demonstration Towns: 'Report for Department for Transport and Cycling England. In London: Department for Transport; 2009.

52. The Marmot Review: Fair Society, Healthy Lives: Strategic Review of Health Inequalities in England Post-2010. London: The Marmot Review; 2010.

53. Commission on Social Determinants of Health: Closing the Gap in a Generation: health equity through action on the social determinants of health. Final Report of the Commission on Social Determinants of Health. In Geneva: World Health Organization; 2008.
54. NZTA: Model Communities Information Sheet. In Wellington: New Zealand Transport Agency; 2011.

55. NZTA: The Walking and Cycling Model Community Story with New Plymouth and Hastings. In Wellington: New Zealand Transport Agency; 2013.

56. Campbell DT, Stanley JC, Gage NL: Experimental and quasi-experimental designs for research. In Houghton Mifflin Boston; 1963.

57. Reichardt CS: Quasi-experimental design. In The SAGE handbook of quantitative methods in psychology; 2009:46-71.

58. Anderson LM, Petticrew M, Rehfuess $E$, Armstrong R, Ueffing E, Baker $P$, Francis $D$, Tugwell $P$ : Using logic models to capture complexity in systematic reviews. Res Synthesis Methods 2011, 2(1):33-42.

59. IPAQ Research Committee: International Physical Activity Questionnaire (Long last 7 days self-administered format). In Stockholm: Sweden IPAQ Research Committee; 2002.

doi:10.1186/1471-2458-14-935

Cite this article as: Chapman et al:: Increasing active travel: aims, methods and baseline measures of a quasi-experimental study. BMC Public Health 2014 14:935.

\section{Submit your next manuscript to BioMed Central and take full advantage of:}

- Convenient online submission

- Thorough peer review

- No space constraints or color figure charges

- Immediate publication on acceptance

- Inclusion in PubMed, CAS, Scopus and Google Scholar

- Research which is freely available for redistribution 